\title{
A Strategy for the Quality Control of Automated Machine Tools
}

T.V. Vorburger

K.W. Yee

B.R. Scace

F.F. Rudder Jr.

U.S. DEPARTMENT OF COMMERCE Technology Administration

National Institute of Standards and Technology

Gaithersburg, MD 20899

February 1992

$-Q C$
100
.$U 56$
4773
1992





\section{A Strategy for the Quality Control of Automated Machine Tools}

\section{T.V. Vorburger \\ K.W. Yee \\ B.R. Scace \\ F.F. Rudder Jr.}

U.S. DEPARTMENT OF COMMERCE Technology Administration

National Institute of Standards and Technology

Gaithersburg, MD 20899

February 1992

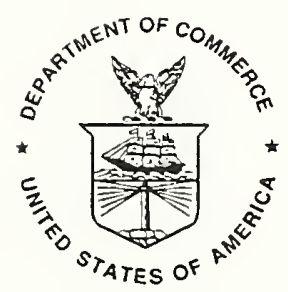

U.S. DEPARTMENT OF COMMERCE Barbara Hackman Franklin, Secretary

TECHNOLOGY ADMINISTRATION

Robert M. White, Under Secretary for Technology

NATIONAL INSTITUTE OF STANDARDS

AND TECHNOLOGY

John W. Lyons, Director 


\section{ABSTRACT}

The automated control of machine-tool accuracy is discussed based on a quality architecture containing three control loops: real-time, process-intermittent, and post-process. This paper highlights the post-process loop. The entire architecture is being implemented at the National Institute of Standards and Technology under the Quality in Automation (QIA) project. At present, active investigation is being carried out for a two-axis turning center. The QIA project emphasizes the measurement and control of process variables to control the quality of the product. However, post-process dimensional measurements of the finished product play a role in the system and may be used for correction of certain variables in the other loops. The strategy for the post-process loop includes classification schemes for the parameters in the system, for the error diagnostics, and for the error model of the machine tool. The need for alteration of parameters in the previous loops is based on the determination of systematic errors in part features. Five stages for automating the overall control system are also proposed. 



\section{INTRODUCTION}

\section{$1.1 \quad$ Purpose}

This paper deals with the dimensional quality control of automated machine tools under a project at the National Institute of Standards and Technology known as Quality In Automation (QIA). Most of the effort in the QIA project has been directed toward automated correction of process variables to control accuracy during manufacture. By contrast this article emphasizes how post-process dimensional measurement plays a role in the control system and how it may be used for correction of certain parameters. The strategy fits into the high-level architecture of the system previously developed, but it also relies on several classification schemes: the classes of adjustable parameters in the system, the classes of workpiece error diagnostics, and the classes of error terms in the model of the machine tool. In addition, five stages of automation are proposed for the system.

The strategy is being developed for a two-axis turning center but a similar scheme may be developed for multiple-axis machining centers.

\subsection{Background}

The machine tool industry is a major factor in the economic competition to manufacture products more rapidly, more efficiently, and with higher quality. Approximately $\$ 4$ billion of machine tools are purchased each year by firms in the United States [1]. Considering their long life, there are likely close to $\$ 80$ billion of machine tools in the United States manufacturing over $\$ 100$ billion of products each year. Many of these products are components in complex mechanical assemblies, such as automobiles, aircraft, and other machines. Because these parts must fit together or move precisely with respect to one another, the requirements of dimensional accuracy often go beyond the $25 \mu \mathrm{m}$ level, and often reach the $5 \mu \mathrm{m}$ level [2]. The dimensional requirements for the parts carry over directly into a need for high accuracy in the machine tools themselves. 
The development of automation for machine tools has been an important step toward satisfying both the speed and accuracy objectives in manufacturing [3]. Machine-tool automation ordinarily implies that the sequential machining steps are carried out under the direction of a numerical control (NC) program stored in the machine-tool controller or some higher level software stored in a computer. Automation directly improves the speed and repeatability of the machining operation and can lead to higher accuracy as well if the machining processes and machine-tool operation are well understood and controlled.

\subsection{Overview of the Quality in Automation Project}

This paper deals with a strategy for using post-process dimensional inspection to improve machine-tool accuracy. This strategy was developed as part of the QIA Project [46]. The general goal of the project is to demonstrate the feasibility of a "self adjusting" manufacturing system that is sensitive to changes in conditions during a manufacturing cycle. The project utilizes commercially available and affordable equipment. The philosophy of deterministic metrology [7] (or deterministic manufacturing [8]) plays a major role here. In an automated production environment, which is not affected by human factors or by variations in materials and where the manufacturing process is repeatable [9], it should be possible to monitor the process and perform adjustments so as to maintain the quality of the product. Deterministic manufacturing emphasizes measurement of the process variables over traditional statistical process control of the product.

The primary scope of the QIA project is the dimensional accuracy of the machine tools themselves. The project activities include real-time monitoring of the machining process, process-intermittent and post-process gauging of the workpieces, and process corrections when required. In addition, preprocess characterization of the machine tools provides the data required for creation of a model of machine-tool errors as a function of position and temperature. This model is used to implement the process corrections in real time. The project scope does not include the study of chatter and its avoidance, the distortion of workpieces by the fixtures, or the possible variations of the workpiece material. 
The QIA project is part of the Automated Manufacturing Research Facility (AMRF) at NIST [10-12]. The QIA architecture, shown in Fig. 1, emphasizes three control loops [13] to keep the manufacturing process in control for dimension, form, and surface finish.

In the real-time loop, the quality controller (QC) monitors the temperature changes of the machine tool and its environment as the tool performs the steps of the NC program. The quality controller then directs corrections in the tool path to offset any dimensional errors that would occur as a result of fixed geometric errors or of thermal drifts. These actions occur during the machining passes on the workpiece. The heart of this loop is a geometrical/thermal (GT) model [14-16], which relates the machine tool dimensional errors to the temperature variations. Parameters in this model are found by the careful measurement of the machine-tool errors during the preprocess characterization. The model is stored as a set of software modules in the quality controller.

In the process-intermittent gauging loop, a touch-trigger probe installed on the machine tool measures the machined features of the workpiece between steps in the manufacturing process. Errors detected in a feature prior to the finish cut will be systematically adjusted by the quality controller to give the correct dimensions for the finished feature.

In the post-process gauging loop, representative finished workpieces from the production run are removed and measured using a coordinate measuring machine (CMM). The CMM resides in a stable temperature environment and has a dimensional accuracy specified to be less than or equal to $2.3 \mu \mathrm{m}$ (92 $\mu \mathrm{in}$ ) for each axis over its range of travel [17]. The dimensions of the finished workpiece are then stored by the quality monitor (QM) and may be used for two purposes: to certify the accuracy of the workpieces and to monitor the effectiveness of the real-time and process-intermittent loops in the machining process. The quality monitor may then direct changes in the process, based on the CMM results and on information concerning the machining conditions. The CMM and quality monitor serve as the referees in the project. 
Several useful developments have taken place in the QIA project. The hardware unit for real-time error correction has been designed, constructed, and tested [18-20]. The same unit has also enabled a fast-probing procedure to be developed for process-intermittent gauging. In addition, a software system [21,22] incorporating the Dimensional Measurement Interface Standard (DMIS) [23] has been installed in the post-process gauging loop, thus providing for direct comparison of $\mathrm{CAD}$-based part drawings and the measured part dimensions on the same computer terminal.

\subsection{Procedures for System Correction}

We now discuss a critical component of the QIA architecture depicted in Fig. 1, namely the actual procedures for correcting the system to improve dimensional accuracy. These procedures address the question, "How does the system fit together to compensate for errors detected during the manufacturing process?". This question is particularly complex for post-process gauging and we will emphasize that loop. However, the gauging and diagnostic procedures in the post-process loop are collectively related to procedures in the real-time and process-intermittent loops. A considerable portion of this report includes discussion of the real-time and process-intermittent gauging loops to help differentiate the role of post-process analysis.

Overall, the scenario for machining accurate components is as follows:

- $\quad$ Roughing cuts for a particular machined feature.

- A semifinish cut of the feature with real-time correction applied using the geometrical/thermal (GT) model and the RTEC hardware.

- Process-intermittent dimensional gauging of the semifinished feature using a touchtrigger probe followed by calculation of dimensional and form errors. 
- A finish cut of the part feature including both real-time correction as before with the added corrections calculated from the process-intermittent data.

On-machine gauging of the finished part feature. Results are to be compared with designed part dimensions and with results from the post-process gauging operation to be performed later.

Removal of a representative part to the metrology laboratory and post-process gauging by a CMM using touch-trigger probes. Results are compared with both the designed part dimensions and with results from the on-machine gauging operation to identify systematic errors in the part features.

Several interrelated questions must be addressed in the strategy for the post-process gauging operation:

- What parameters in the system are automatically adjustable so that control may be achieved?

- What sources of error are present in the machine tools and how do they propagate into errors in the machined part? What are the component error terms?

What gauging procedures should be used to measure the finished products? That is, what are the error diagnostics?

What correction algorithms are required for robust automated operation?

We will focus primarily on the first three questions. Development of the correction algorithms will follow from an understanding of the first three issues and from a consideration of the part geometry to be machined. To address these questions, we discuss the system architecture from several points of view. 
First, in section 2, we discuss the classes of parameters in the system that may be adjusted automatically. These classes require different levels of sophistication in the software for modeling the machine-tool errors and for communication between elements of the system. One important class of variables in this scheme is the set of error terms in the geometrical/thermal model of the machine tool and the functional parameters which comprise these terms.

Implementation of the overall correction system for all three loops is taking place over several stages of automation, with the simplest class of procedures coming on line before more complex procedures. The stages of automation are described in Sec. 3. In fact, implementation of quality control procedures is open-ended because the calculations and decision trees can always be refined and expanded.

In section 4, we discuss the error diagnostics for a two-axis $\mathrm{NC}$ turning center, i.e., the gauged features that may be measured to diagnose the sources of error.

\section{ADJUSTABLE PARAMETERS IN THE SYSTEM}

We now discuss, in turn, five classes of parameters that may be adjusted to optimize dimensional accuracy in the system. These are tool offsets, the $\mathrm{NC}$ code for machining, the real-time compensation values, parameters in the GT model, and weighting factors in the control software. The first four classes appear in the detailed architecture of Figs. 2-5. Figure 2 is an overall template for information flow in the system. Figure 3 illustrates information flow through the RTEC in the real-time loop. Figure 4 illustrates information flow in the process-intermittent loop. Figure 5 illustrates information flow in the postprocess loop. 


\section{$2.1 \quad$ Tool Offsets}

The machine-tool controller stores parameters that account for the geometries of the individual cutting tools in order to position the cutting edges precisely with respect to the workpieces. In turning, these are the coordinates of the tool point $\left(\mathrm{X}_{\mathrm{T}}, \mathrm{Z}_{\mathrm{T}}\right)$ with respect to some appropriate reference on the fixture and possibly the tool-tip radius. The parameters $\left(\mathrm{X}_{\mathrm{T}}, \mathrm{Z}_{\mathrm{T}}\right)$ are found by a tool-setting procedure that uses a special touch-trigger probe to locate the cutting edges [24]. The parameter values for turning are often divided into two parts: a nominal value (such as tool length) which is fixed for any tool, and the deviation from the nominal value (tool offset) which is adjustable. In the QIA system, these parameter values are stored in the quality controller which oversees the machining operation in real-time. A sensed error that can be corrected by a simple translation of the tool leads to an adjustment of the appropriate tool offset parameter in the quality controller, which is then downloaded to the machine-tool controller (Figs. 4 and 5). Automated adjustment of tool offsets is already a common industrial practice [2,24,25]. Normally, these adjustments do not take place in the real-time loop but rather after some processintermittent or post-process gauging operation. For the QIA project, the critical choices involve deciding when to change the simple tool offsets and when to change more deeply embedded variables of the GT model discussed below.

\subsection{Numerical Control Code}

The numerical control (NC) code that directs the path of the cutting tool constitutes a second class of system variables. In the QIA system we segment the NC code into discrete machining blocks that are downloaded sequentially from the quality controller to the machine-tool controller. Each block corresponds to the roughing or finishing of a single feature or to a gauging sequence as discussed in Sec. 1.4 for process-intermittent correction. The NC blocks that describe each finish-cut path would include adjustable parameters. If changes in the cutting path are called for as a result of a gauging process, the path correction would be expressed in terms of the parameter adjustments and a new path thus 
recalculated by the quality controller. The revised block of NC code would then be downloaded to the machine-tool controller (Fig. 4). Generally, the NC code is to be varied in this way only for finishing cuts and only after a process-intermittent gauging operation.

\subsection{Real-Time Compensation Values}

A unique aspect of the QIA project is the capability for tool path adjustment in realtime using the Real-Time Error Corrector (RTEC) [18-20], a hardware module that intercepts and changes the stream of pulses sent from each axis position feedback device to the machine-tool controller (Fig. 3). The RTEC is directed by the quality controller, which samples temperature across the machine tool and calculates a tool-path correction in realtime using the GT model. This is essentially an instantaneous single-point calculation. The quality controller calculates the correct value for each axis coordinate at a particular time and alters the tool path coordinate to that value depending on the dimensional distortions predicted by the GT model. It does this by sending compensation values to the RTEC at appropriate times during the cutting sequence.

The RTEC can also be used for process-intermittent path correction as an alternative to changing the NC code described above. After a process-intermittent gauging operation, the quality controller calculates the path correction required and may then modify the compensation values sent to the RTEC. This is an additive correction. That is, the compensation values in the process-intermittent path correction are added or subtracted from those arising in the GT correction algorithm.

\subsection{Error Terms and Parameters in the Geometrical Thermal (GT) Model}

The use of temperature sensing and of a GT model for path correction in real-time was pioneered by Donmez et al. [14,15]. Their work serves as the basis for the development of real-time correction in the QIA project. To develop the model, the path errors of the machine tool must be measured over the machine tool's thermal operating 
range. Then the results must be fitted to parameterized models using well known statistical techniques [26]. There are a large number of error components in the GT model, and each calculated component includes several fitted parameters that take into account its variation with respect to the position of each of the moving elements of the machine tool and with respect to the temperature of the machine tool. Forty temperature sensors are installed on the turning center and the important ones to use in the parameterized model depend on which component of error is being characterized [27]. The major elements of the two-axis turning machine are shown in Fig. 6 . They include a carriage constrained to move in the $z$-direction, a cross slide constrained to move in the x-direction, the spindle, the workpiece, the tool, and the turret. The principal sources of error are associated with motions of the carriage, cross slide, and spindle axis. These are shown in Fig. 6 and listed below (the symbol notation is taken from Donmez et al. [14]):

$\delta_{x}(x) \quad$ linear displacement error of the cross slide,

$\delta_{\mathrm{z}}(\mathrm{x}) \quad$ sideways displacement errors of the cross slide including both the straightness of travel and any orthogonality error between the cross slide axis and the spindle axis,

$\epsilon_{\mathrm{y}}(\mathrm{x})$ yaw error of the cross slide (rotation in the $\mathrm{x}-\mathrm{z}$ plane),

$\delta_{\mathrm{z}}(\mathrm{z}) \quad$ linear displacement error of the carriage,

$\delta_{x}(z) \quad$ sideways displacement errors of the carriage including both the straightness of travel and any parallelism error between the carriage axis and the spindle axis,

$\epsilon_{\mathrm{y}}(\mathrm{z}) \quad$ yaw error of the carriage,

$\delta_{\mathrm{x}}(\mathrm{s}) \quad$ spindle drift in the $\mathrm{x}$-direction, 
$\delta_{\mathrm{z}}(\mathrm{s}) \quad$ spindle growth in the $\mathrm{z}$-direction,

$\epsilon_{\mathrm{y}}(\mathrm{s}) \quad$ spindle tilt in the $\mathrm{x}-\mathrm{z}$ plane.

The symbols $\mathrm{x}$ and $\mathrm{z}$ represent the positions of the cross slide and carriage with respect to their appropriate origins as determined by the machine tool scales.

The above error sources, depicted in Fig. 6, are termed quasi-static errors because they are associated with the slowly moving elements of the machine. They may be measured in a comprehensive way by interferometric and other methods discussed elsewhere [14,16,26-29]. Not shown are dynamic errors associated with spindle rotation, such as spindle runout, or process induced errors such as the vibrational instabilities known as chatter observed during cutting. Error sources that cause motion in the y-direction (the nonsensitive direction [14]) are second order errors and are ignored here. Lastly, errors arising from the turret angular position are not shown here but have been discussed previously [15].

Donmez et al. [15] described the errors of each element of the turning center using matrices known as homogeneous coordinate transformations. The overall errors for the tool with respect to the workpiece can be calculated by multiplying these matrices. The resulting error vector components in the $x-, y$ - and $z$-directions can then be written algebraically in terms of the errors of all the machine elements. Figure 7 [15] shows the three translational components $\left(\mathrm{P}_{x}, \mathrm{P}_{\mathrm{y}}, \mathrm{P}_{\mathrm{z}}\right)$ of the position errors of the tool point with respect to the workpiece. In addition, there are rotational errors $\left(\epsilon_{\mathrm{x}}, \epsilon_{\mathrm{y}}, \epsilon_{\mathrm{z}}\right)$ between the tool and the workpiece. However the overall rotational errors may be ignored for the turning operation because to a first approximation only the position of the tool tip is important with respect to the workpiece and not its orientation. The y-translation error is also ignored as discussed before. Therefore, the only important errors are the overall translation errors, $P_{x}$ and $P_{z}$, of the tool with respect to the workpiece. After the matrix multiplication is carried out, 
these total error vector components may be described algebraically in terms of the error components arising in each element of the machine as follows [15]:

$$
\begin{aligned}
& \mathrm{P}_{\mathrm{x}}=\epsilon_{\mathrm{y}}(\mathrm{s})^{*} \mathrm{z}(\mathrm{w})+\delta_{\mathrm{x}}(\mathrm{s})-\left[\epsilon_{\mathrm{y}}(\mathrm{z})+\epsilon_{\mathrm{y}}(\mathrm{x})\right]^{*} \mathrm{Z}_{\mathrm{T}}-\delta_{\mathrm{x}}(\mathrm{x})-\delta_{\mathrm{x}}(\mathrm{z}), \\
& \mathrm{P}_{\mathrm{z}}=-\epsilon_{\mathrm{y}}(\mathrm{s})^{*} \mathrm{x}(\mathrm{w})+\delta_{\mathrm{z}}(\mathrm{s})+\left[\epsilon_{\mathrm{y}}(\mathrm{z})+\epsilon_{\mathrm{y}}(\mathrm{x})\right]^{*} \mathrm{X}_{\mathrm{T}}+\epsilon_{\mathrm{y}}(\mathrm{z})^{*} \mathrm{x}-\delta_{\mathrm{z}}(\mathrm{x})-\delta_{\mathrm{z}}(\mathrm{z}),
\end{aligned}
$$

where $(x(w), z(w))$ is the ideal point on the workpiece where the tool tip is supposed to be located with respect to the reference point or origin, and $\mathrm{X}_{\mathrm{T}}$ and $\mathrm{Z}_{\mathrm{T}}$ are the coordinates of the tool tip with respect to an appropriate origin in the turret.

As shown by Eqs. (1) and (2), the displacement error along the $\mathrm{x}$ - and $\mathrm{z}$-axes is an additive combination of either six or seven terms. These error terms may be organized into three classes: offset terms that have constant values independent of either $\mathrm{x}$ - or $\mathrm{z}$-position, linear terms representing displacement errors along a particular axis arising from motion along the same axis, and sideways terms representing displacement errors along a particular axis arising from motion along the other axis. Sideways terms include both straightness and orthogonality errors. In Eq. 1 the error component $\delta_{x}(x)$ is a linear error term, $\delta_{x}(z)$ is a sideways term, and $\delta_{x}(s)$ is an offset term. These have been discussed specifically in connection with Fig. 6 . In addition,

$\epsilon_{\mathrm{y}}(\mathrm{s})^{*} \mathrm{z}(\mathrm{w})$ is effectively a sideways error arising from yaw error of the spindle.

$\epsilon_{\mathrm{y}}(\mathrm{z}) * \mathrm{Z}_{\mathrm{T}}$ is a sideways error due to the yaw of the carriage. For a constant $\mathrm{z}$-value, this error is proportional to the tool tip z-position with respect to the turret origin.

$\epsilon_{\mathrm{y}}(\mathrm{x})^{*} \mathrm{Z}_{\mathrm{T}}$ is a linear error due to the yaw of the cross slide. For constant $\mathrm{x}$, the error is proportional to the tool tip z-position with respect to the turret origin. 
The error terms in Eqs. (1) and (2) depend on the temperature signature of the machine tool and may also depend on the position of the carriage or cross slide. Each error term of the model may be described in turn by a sum of several terms each containing an adjustable parameter. The values of these parameters are found by careful measurement of each machine-tool error as a function of temperature and in some cases as a function of $\mathrm{x}$ - or z-position of the tool $[16,28]$. The GT model may be modified after post-process inspection by adjusting the values of the parameters previously calculated from the preprocess data.

A parametric model is calculated for each error term in the machine tool. One example is the linear displacement error term $\delta_{z}(z)$ of the z-axis of the turning center arising from Abbé error [30] between the scale and the tool tip. Donmez et al. [16,29] have developed a model for this component shown by the surfaces in Fig. 8. To account for the backlash of the carriage travel, there are different models for the forward and return directions. Moreover, the error surface for each direction is composed of three overlapping segments smoothly joined together. Each segment of data is represented by the model

$$
\delta_{\mathrm{z}}(\mathrm{z})=\mathrm{A}+\mathrm{BT}_{12}+\mathrm{Cz}+\mathrm{Dz}^{2}
$$

with different parameters depending on which of the six segments the z-axis position falls into. This model has a linear dependence on temperature $T_{12}$ and a quadratic dependence on position. The variable $T_{12}$ represents the thermocouple temperature measured at the bottom of the $\mathrm{x}$-way near the z-slide, a variable that seems to correlate best with the measured displacement errors.

Equation 3 has four adjustable parameters for each segment of data thus yielding 24 adjustable parameters for the z-displacement component of machine- tool error. Additional parameters of this model that are likely to remain nonadjustable are the demarcation positions between the three segments and the number of terms in the model. 


\subsection{Weighting Factors}

Each adjustment made in one of the above parameters is likely to have a fractional weighting factor that attenuates its effect. If, for example, a tool offset is reckoned to be incorrect by $0.1 \mathrm{~mm}(0.004 \mathrm{inch})$ during a process-intermittent gauging operation, the resulting adjustment should be smaller than this value, say by $25-50 \%$. Otherwise, an unstable situation may result in which successive adjustments of certain components of error change their sign (+ to - ) and steadily increase. Such a situation can occur when the actual source of error is different from the one reckoned to be causing the problem so that adjustment is made to the wrong component of the system. The same situation can also occur if the source of the error is of a random nature. In general, the problem is formally similar to oscillation problems in servo-control theory [31].

These weighting factors will likely have values between 0.50 and 0.75 and will be included as multiplying factors of the other classes of adjustments. However, the weight values themselves may be adjusted automatically by the QIA control system.

\section{STAGES OF AUTOMATION}

Automation of the correction procedures in the QIA system should take place in five stages related to the classes of parameters discussed above:

Stage 1 Automated adjustment of machine offsets.

Stage 2 Automated revision of real-time compensation values or of NC code.

Stage 3 Automated identification of the individual error terms of the GT model requiring adjustment on the machine tool. 
Stage 4 Automated adjustment of the empirical parameters comprising each error term.

Stage 5 Automated adjustment of the weighting factors multiplying the adjustments in stages 1,2 , and 4 . This activity will actually operate in parallel with the other stages rather than sequentially.

We now examine each of these stages in more detail.

\subsection{Stage 1-Machine Offsets}

Procedures for resetting machine tool offsets are routinely used in machine-tool technology. These adjustments may be made after a tool setting procedure that is part of a commercial machine-tool's operation. In addition, tool offsets may be adjusted following process-intermittent part gauging operations [2,24,25].

This capability for adjusting tool offsets after process-intermittent gauging has been incorporated into the QIA project [18,19]. However, the machine's procedure for acquiring tool offsets may also be adjusted in the post-process loop after gauging of a finished part with the CMM assuming that the tool in question is not changed before the data is analyzed and returned. As discussed in Sec. 2.1, there are two offset parameters for each tool on the turning machine.

A scenario is shown in Fig. 9 for automatically correcting the x-offset after processintermittent gauging of a single feature. The difference $\left(\Delta_{\mathrm{r}}\right)$ between the measured and designed radius is weighted by a factor of 0.75 , for example, and transmitted to the quality controller to be added to the existing value for the $\mathrm{x}$-offset. 


\subsection{Stage 2 - Real-time Compensation Values or NC Code}

If process-intermittent gauging indicates a form error in the semifinished workpiece, then a modification of the entire tool path is required for the finish cut rather than a simple offset correction. Such a process-intermittent path correction may be accomplished either by using the RTEC hardware or by a modification of the NC code.

Adjustment of the tool path in real-time has been achieved with the RTEC hardware [18-20]. This operation is directed by the quality controller and is guided by the GT model installed there (see Fig. 3). The RTEC is also used for process-intermittent correction [32]. In the quality controller, the programmed path of the tool used for the semifinish cut is compared with the path along the part surface as measured by the part probe. The path differences are written to a lookup table, which is then used to calculate a series of compensation values $(\Delta x, \Delta z)$ for the path correction. For each axis, the values for this path correction are added arithmetically to the real-time compensation values obtained from the GT model.

Alternatively, the NC code could be automatically modified in the quality controller in response to the process-intermittent gauging results [33]. Briefly, the NC code that describes the machining operation is divided into segments that are separately loaded to the machine-tool controller. The key segments are those describing the finish cuts that determine the final dimensions of the workpiece. These segments are to contain variables rather than constants that describe the tool path. Changes in the variables result in modification of the tool path. A flowchart of a simple cutting operation with four blocks of NC code is shown in Fig. 10.

\subsection{Stage 3 - Post-process Identification of Error Components}

We now come to the complex stages of integrating the post-process measurement into the automated process correction procedure. We discussed above that a single error 
component, z-linear displacement, had 24 empirical parameters in its model. That suggests that for a machine with 10 significant error terms, there may be approximately 200 adjustable parameters. We therefore propose dividing the step of automating post-process correction into two stages. Stage 3, described here, is the automated identification of the correct error term based on the gauging results. This diagnosis would be followed by manual investigation and adjustment of the parameters in the GT model for that component. Stage 4 then will be the automation of the parameter adjustment process.

We discuss Stage 3 in some detail. First, we generally observe that the post-process gauging results could also be used to direct the RTEC or NC correction procedures described above in Stage 2, thus avoiding the complexities of adjusting the GT model. However, the disadvantage of those approaches is that it would be problematic to apply post-process gauging results measured on one type of workpiece to detailed path corrections on another type requiring different tool paths. In order to generalize error results from one type of feature or workpiece to another, it is necessary to deal with the underlying causes in the machine itself. That process must involve the GT model.

We now discuss the identification of error components of the GT model using as an example the $\mathrm{x}$-vector component of displacement error in the turning machine, given by Eq. (1). All of the error terms there may depend on the temperatures of the machine and, therefore, must be calculated in real time. The lone offset term $\delta_{x}(\mathrm{~s})$ has a constant value independent of the position of the carriage or cross slide. Hence, for a given temperature, an error in this term may be adjusted by a single change in tool offset. The three sideways terms are $\epsilon_{\mathrm{y}}(\mathrm{s})^{*} \mathrm{z}(\mathrm{w}), \epsilon_{\mathrm{y}}(\mathrm{z})^{*} \mathrm{Z}_{\mathrm{T}}$, and $\delta_{\mathrm{x}}(\mathrm{z})$. These terms have the same functional form; the error in $\mathrm{x}$ is a function of carriage position $\mathrm{z}$. The two linear error terms are $\epsilon_{\mathrm{y}}(\mathrm{x})^{*} \mathrm{Z}_{\mathrm{T}}$ and $\delta_{x}(x)$.

On first glance it would seem futile to classify these errors further. For example, a measured sideways error might derive from any of three sources. Nevertheless, it is possible to identify the individual error term by a predetermined strategy of calculating the 
appropriate correlations of the measured errors with the system variables such as position and temperature. In detail, the following correlations should be anticipated and automatically checked in the system for error measured in the radial ( $x-$ ) direction by the CMM.

$\delta_{x}(\mathrm{~s})$

The x-offset drift of the spindle should correlate with spindle temperature.

$\delta_{x}(z)$

Sideways errors measured on finished workpieces are due to error in this component if they correlate with temperature variation of the carriage.

$\epsilon_{\mathrm{y}}(\mathrm{s})^{*} \mathrm{z}(\mathrm{w})$

Tilt error in the spindle should correlate with spindle temperature. It also produces a linear change in the measured diameter of the finished workpiece as a function of axial position $z(w)$.

$\epsilon_{\mathrm{y}}(\mathrm{z})^{*} \mathrm{Z}_{\mathrm{T}}$

Error due to yaw motion of the carriage should correlate with carriage temperature and is directly proportional to the $z$ position of the tool tip with respect to the turret axes.

$\delta_{x}(x)$

If the linear displacement error of the cross slide is not properly accounted for in the model, then the measured errors in the diameter of the finished workpiece should be a function of both the nominal diameter of the workpiece and the cross slide temperature. 


$$
\begin{aligned}
& \epsilon_{\mathrm{y}}(\mathrm{x})^{*} \mathrm{Z}_{\mathrm{T}} \quad \text { linear error in } \mathrm{x} \text { due to the yaw of the cross slide is diagnosed } \\
& \text { in a similar manner to } \delta_{\mathrm{x}}(\mathrm{x}) \text {. But in addition any errors in } \\
& \text { finished workpiece diameter should correlate directly with tool } \\
& \text { tip position } \mathrm{Z}_{\mathrm{T}} \text {. }
\end{aligned}
$$

In summary, a strategy of correlating measured errors of workpiece diameter with a limited number of variables can lead automatically to identification of any error term of the machine not properly accounted for in the GT model. Table 1 summarizes the above discussion for the $\mathrm{x}$-component of error as well as proposed strategies for the $\mathrm{z}$-component. The above considerations do not exhaust the number of variables that should be tracked in such a quality improvement strategy. It would be useful to track several other correlations as well.

\subsection{Stage 4-Adjustment of Model Parameters}

The automated adjustment of the actual parameters in the GT model should follow once experience is gained in automatically identifying the error terms. With roughly 200 parameters likely to be needed for the entire GT model, it is difficult to foresee a global plan for adjusting the model. It is more likely that the installation of automated parameter adjustment will be accomplished quickly for a few of the simpler component models, such as those that have a linear dependence on temperature and on position.

\subsection{Stage 5 - Weighting Factors}

As discussed before, all of the calculated process adjustments are multiplied by weighting factors. A plan for adjusting these factors can be installed in parallel with each of the other stages. The adjustment of these factors will depend on successive measurements as we iterate the adjustments taken in the other stages. If, for example, a particular correction increases in magnitude and changes sign over several iterations, the system could be programmed to reduce the associated weighting factor by a standard 
percentage. If on the other hand, the value of the adjustment changes very little over several iterations, indicating little change in the process, the associated weighting factor could be increased.

\section{MEASURABLE ERRORS}

We now describe the measurement of several classes of errors of machined parts for turning operations. We also discuss the possible sources of each type of error and describe briefly how these various error sources might be diagnosed individually.

\subsection{Unstable Fixturing}

First we distinguish the general problem of unstable fixturing from the other types of errors. Unstable fixturing can occur for the workpiece, the tool setting probe, or the part probe, and it can cause large errors in any of the workpiece dimensions or the measurements.

Since fixturing is a manual operation in our system, the correction of any sort of fixturing error requires manual intervention. However, unstable fixturing of the part probe may be diagnosed automatically by repeated measurements with it at a single point on the part or on the machine spindle just after the probe is fixtured. The instability may be detected as a large drift, a step change, or large standard deviations in the measured probing values. Instability in the tool probe or the workpiece may be sensed by similar procedures.

\subsection{Elementary Error Diagnostics}

Turning from the traumatic but avoidable condition of unstable fixturing, we discuss error features that may be diagnosed with straightforward probing schemes. These schemes are applicable both to process-intermittent and post-process gauging and are more easily described in terms of the cylindrical geometry of the turning center itself. An error 
condition measured for each feature leads to a modest number of choices of adjustment to correct the system. These features are shown schematically in Fig. 11 and are described below.

\section{Incorrect Radius}

An incorrect radius of a turned part (Fig. 11a) is found by probing the radius at a point along the shaft near the chuck and comparing the average to a specification. Possible machining errors that cause this problem are:

- incorrect tool offset,

- incorrect part-probe offset,

- $\quad$ error in the $\mathrm{x}$-component terms of the GT model of the machine tool.

An incorrect tool offset may be caused by tool wear or by an error in the tool setting procedure itself. It is diagnosed by process-intermittent gauging. Once the size of the error is properly diagnosed, it may be corrected automatically by adjusting the tool offset in the machine tool controller.

In the QIA system, the part-probe offset parameter resides not in the machine-tool controller but in the quality controller where it is required for the fast probing operation. An incorrect part-probe offset may be caused by a change in the probe circuit's lag interval characteristics or by an error in the original probe-setting procedure.

An incorrect part-probe offset cannot be diagnosed by process-intermittent gauging. Proper diagnosis requires a comparison between the radius measured by the CMM and the radius measured by on-machine gauging of a finished workpiece. Once diagnosed, it may be corrected by a straightforward adjustment of the parameter in the quality controller. However, the value of this offset parameter is a function of the values of other error terms in the system such as the x-offset term $\delta_{x}(\mathrm{~s})$ of the GT model. An inappropriate adjustment 
of the part-probe offset could lead to an incorrect diagnosis of terms in the GT model. Therefore, the part-probe offset should only be adjusted after measuring a standard test part produced under standardized cutting conditions.

An error in the geometrical/thermal model of the machine tool will lead to small errors in the measured radius even after the part-probe offset and tool offset have been measured properly as sketched above. The model may be adjusted by changing one or more of its parameters that reside in the quality controller or by adding more parameters. We anticipate that the automation of this process will occur in Stage 4 as described before.

\section{Incorrect Feature Length}

An incorrect feature length (Fig. 11b) is found by probing two elements located at different $z$-positions on the workpiece and comparing their $z$-axis difference with the specified one. This problem is routinely avoided by an initial facing and probing operation on the part. All machining and probing operations are subsequently performed with respect to that initial front face.

In addition to the general problem of unstable fixturing the special conditions that can cause feature-length error are:

- $\quad$ error in either the z-linear terms or the z-sideways terms of the GT model,

- differential tool deflection because of different depths of cut between machining passes $\left(Z_{+}\right.$and $\left.Z_{-}\right)$,

- inconsistent offsets, if different tools were used for the two features, or

tool wear occurring between two machining passes. 
We expect that all but the first case above would be easily diagnosed during processintermittent gauging. Differential tool deflection may be avoided by equalizing the depths of the semifinish- and finish-cut machining passes of all features so that the tool experiences the same deflection. The inconsistent offsets may be corrected by adjusting the $z$-tool offset of one of the tools, preferably the one used less often. If a single tool is used and the depths of cut are equal at both ends of the feature, then tool wear may have occurred between passes. If this problem was large enough to cause a dimensional change in the machined feature, then it is also possible that excessive wear has dulled the tool and it should be manually inspected.

\section{Tapered Shaft}

A taper in a shaft (Fig. 11c) may be found by probing the radius of a nominally straight shaft at two or more points. The taper is observed as a difference between the $r_{+}$ and $r$. readings.

One cause of a taper is workpiece deflection. If the part is not stiff, it will deflect more at its outer end under the cutting force exerted by the tool than it will near the spindle. Hence, the radius of the machined shaft, even if correct near the spindle, will be oversized near the outer end. Workpiece deflection is measurable by process-intermittent gauging. In that case, the finish cut may be compensated by adjusting the slope of the tool path or by a reduction in depth of cut. If the cause is an error in one of the three $\mathrm{x}$-straightness terms of the GT model (Eqn. 1), the problem will be missed by the processintermittent gauge but measured by the CMM.

\section{Tapered Face}

A tapered face (Fig. 11d) is recognized as a difference in the measured z-coordinate obtained from probing at two radii on a faced feature. It is possible that such an error feature is caused by tool or part deflection. This can also be indicative of a face cut at 
constant spindle speed over a large radius face. If the problem is recognized during processintermittent gauging, it may be corrected by an RTEC or NC adjustment. If it is missed by the process-intermittent probing but picked up by the CMM, then the problem likely resides in the z-sideways components of the GT model. Adjustment in the RTEC or NC procedure would only be a temporary fix. Correction of the GT model itself is required to fix the problem permanently.

\section{Imperfect Edges}

Imperfect edges (Fig. 11e) may be caused by servo-lag errors as the tool attempts to follow sharp changes in the slope of a programmed tool path. However, a sharp edge in a programmed contour is not common for turned parts. Sharp edges are usually fabricated by making two cutting passes. The servo-lag error is also likely to produce errors of small spatial extent that are difficult to observe by touch probing. For example, if the servo-lag error is $0.0005 \mathrm{~mm} /(\mathrm{mm} / \mathrm{min})(0.0005 \mathrm{in} /(\mathrm{in} / \mathrm{min}))$, then with a feed of $0.08 \mathrm{~mm} / \mathrm{rev}$ $(0.003 \mathrm{in} / \mathrm{rev})$ and a spindle speed of $4000 \mathrm{rpm}$, the servo-lag error is only $0.16 \mathrm{~mm}$ (0.006 in) in extent. A likely result of such a servo-lag error is a rounded edge with radius of approximately $0.16 \mathrm{~mm}$ (0.006 in). Detection of an error of such small extent with a touch probe would be difficult because closely spaced readings would have to be taken around the edge of a part. Because servo-lag errors are rarely generated during turning operations and are difficult to diagnose, these are not considered to be a measurable problem for the QIA system.

\section{Straightness}

Two major sources of straightness errors (Fig. 11f) are instabilities in the cutting process and sideways errors in the slide or carriage motions of the machine tool.

The former is a dynamic error; the latter is a quasi-static error. The dynamic instabilities have been studied extensively by Tlusty et al.[34], Minis et al.[35], and others. These may 
be monitored and minimized by measurement of vibrational excitations of the tool in realtime and appropriate modification of the cutting conditions.

Sideways errors detected by process-intermittent gauging may be corrected by modifying the correction pulses transmitted to the RTEC or by modifying the NC code transmitted to the machine-tool controller as discussed before. Briefly, the probing density, fitting algorithms, and correction strategy should be well matched to the highest spatial frequency of the errors that are likely to occur on the machined part. If the dimensional errors arise from the geometrical/thermal model, they will escape detection by processintermittent gauging but will be detected by the CMM.

Figure 12 illustrates the choices required ahead of time for accomplishing processintermittent correction along a turned shaft that is designed to be straight. First, the cylindrical stock undergoes a roughing cut and a semifinish cut under the same conditions as the upcoming finish cut, a procedure that anticipates the resulting errors. The shaft is then probed at six points, for example, a decision having previously been made that straightness errors with spatial frequencies higher than about 3 waves along the shaft length are not significant. The six-point profile obtained with the probe is then fitted to a polynomial. Once again the number of terms in the polynomial should be consistent with the highest significant spatial frequencies expected on the surface, a choice based on previous experience. The polynomial fit serves to smooth out the resulting correction profile. The parameterized polynomial is then either translated into RTEC compensation values or is broken into segments of NC code for downloading as input data to the NC program in the machine-tool controller. Finally, the finish cut is taken with the appropriate straightness correction.

A different scenario would occur if the straightness correction is required in the postprocess loop based on CMM measurements. In that case, several straightness curves measured at different machine operating temperatures would be correlated with the machine operating parameters as discussed in Sec. 3.3. This would determine the 
appropriate machine element needing adjustment in the GT model. Then the CMM data would be fitted to the GT model. The resulting parameters could then be multiplied by an appropriate weighting factor and added to comparable parameters in the original model.

\section{CONCLUSION}

We have proposed a strategy for automated machine-tool correction that addresses three key areas -- the classes of parameters that may be adjusted, the stages for automating the system, and the procedures for diagnosing the errors in the machine tool from measurements of the finished workpiece. Concerning this strategy we make two observations:

1) The RTEC may be used for both real-time or process-intermittent corrections.

2) The adjustment of the GT model is reserved for the post-process loop, and the RTEC and NC code adjustments cannot be performed in the post-process loop.

These procedures are being implemented for a two-axis turning center. For a threeaxis machining center, the concepts are similar but the GT model is significantly more complex.

Several questions have not been discussed here, namely, the specific diagnostic procedures that would be developed to sort out reliably all of the parameters in each error term, the correction algorithms that would be integrated into the quality controller software, and the physical layout of the equipment and communications links. Development of the diagnostic procedures will especially include decisions concerning the number of probe points required for each type of machined feature to be analyzed. 


\section{ACKNOWLEDGMENTS}

The authors would like to acknowledge the guidance and technical contributions of M.A. Donmez, and helpful suggestions from A. Jones concerning the manuscript. V.S. Gagne and R.G. Gale typed the manuscript and V.S. Gagne drew most of the illustrations. The work was funded in part by the U.S. Navy's Manufacturing Technology Program. 


\section{REFERENCES}

1. Economic Handbook of the Machine Tool Industry (Assoc for Manuf. Tech., McLean VA, 1991) p. A2.

2. "Probe Makes Machining Center a Profit Center" Modern Machine Shop, p. 148 (July, 1990).

3. R.J. Hocken, Machine Tool Task Force, Technology of Machine Tools 5, UCRL52960-5, LLNL (Oct 80) pp 3-7.

4. C.D. Lovett (ed.), Progress Report of the Quality in Automation Project for FY88, NISTIR 89-4045 (National Institute of Standards and Technology, Gaithersburg, MD 1989).

5. T.V. Vorburger and B.R. Scace (eds.), Progress Report of the Quality in Automation Project for FY89, NISTIR 4322 (National Institute of Standards and Technology, Gaithersburg, MD, 1990)

6. M.A. Donmez (ed.), Progress Report of the Quality in Automation Project for FY90 NISTIR 4536 (National Institute of Standards \& Technology, Gaithersburg, MD 1991).

7. J.A. Simpson, "The National Bureau of Standards Approach to Quality," Test \& Measurement World $\underline{3}$, 38 (Dec. 1983).

8. D.S. Blomquist, "Quality in Automated Manufacturing," in Three Pillars of Manufacturing Technology, R.H.F. Jackson, ed. (Academic Press, NY, 1991).

9. R.R. Donaldson, "The Deterministic Approach to Machining Accuracy," presented at Soc. Manuf. Engrs. Technology Symposium (Golden CO, November, 1972).

10. J. Albus, A. Barbera, and N. Nagel, "Theory and Practice of Hierarchical Control," in Proc. 23rd IEEE Computer Society Int. Conf. (1981) p. 18.

11. J. Simpson, R. Hocken, and J. Albus, "The Automated Manufacturing Research Facility of the National Bureau of Standards," J. Manuf. Systems 1,17 (1982).

12. R.H.F. Jackson and A.W.T. Jones, "An Architecture for Decision Making in the Factory of the Future," Interfaces 17 (6), 15 (1987)

13. T.V. Vorburger and J.C. Boudreaux, "An Architecture for Quality Control in the QIA Project," in ref. 4, p. 5. 
14. M.A. Donmez, D.S. Blomquist, R.J. Hocken, C.R. Liu, and M.M. Barash, "A General Methodology for Machine Tool Accuracy Enhancement by Error Compensation," Prec. Eng. $\underline{8}, 187$ (1986).

15. M.A. Donmez, C.R. Liu, and M.M. Barash, "A Generalized Model for Machine Tool Errors," in Modeling, Sensing, and Control of Manufacturing Processes, PED Vol. 23/DSC-Vol. 4, K. Srinivasan, D.E. Hardt, and R. Komanduri, eds. (Amer. Soc. Mech. Engrs., New York, NY, 1987).

16. M.A. Donmez, K.W. Yee, D.H. Neumann, and L. Greenspan "Implementing RealTime Control for Turning Center," in. ref 6, p. 25.

17. S.D. Phillips, B. Borchardt, and D. Stieren "Post-Process Inspection and Test Part Measurement Results," in ref. 5, p. 113.

18. K.W. Yee, "Real-Time Error Corrector and Process-Intermittent Probing," in ref. 5, p. 9.

19. K.W. Yee and R.J. Gavin, Implementing Fast Part Probing and Error Compensation on Machine Tools, NISTIR 4447 (National Institute of Standards \& Technology, Gaithersburg, MD, 1990).

20. K.W. Yee, Alternative Designs of a Real-Time Error Corrector For Machine-Tools with "Encoder" Position Feedback, NISTIR 4832 (National Institute of Standards \& Technology, Gaithersburg, MD, 1992)

21. D.C. Stieren and S.D. Phillips, "Automated Inspection Using CMIS and IGES to Integrate CAD/CAM Software Products with CMMs," in ref. 6, p. 61.

22. S.D. Phillips, D.C. Stieren, and J.G. Salsbury, "Development of an Automated Part Inspection System Using the DMIS Standard," presented at the Soc. Manuf. Engrs. Clinic on Precision Metrology with Coordinate Measurement Systems (San Jose, CA, Sept, 1990).

23. "DMIS 2.1 Specification CAM-I Standard 101" (CAMI Inc., Arlington, TX, 1990).

24. T. Beard, "In Touch with Quality and Productivity," Modern Machine Shop, p. 66 (February, 1990).

25. D.R. McMurtry, "Footprinting," (Renishaw plc: Wotton-under-Edge, UK, 1987).

26. F.F. Rudder, Jr., J. Filliben, and W. Guthrie, "Methodology for Characterizing Temperature-Related Positioning Errors of a Vertical Axis Milling Machine," to be published. 
27. F.F. Rudder, Jr., "Machine Tool Characterization," in ref. 4, p.48.

28. F.F. Rudder, Jr., "Characterization of the Vertical Machining Center," in ref. 6, p .5.

29. M.A. Donmez, "Development of a New Quality Control Strategy for Automated Manufacturing," in Proc. Manufacturing International'92, D. Durham, ed. (American Society of Mechanical Engineers, New York, 1992) p. 237.

30. J.B. Bryan, "The Abbé Principle Revisited - An Updated Interpretation", Prec. Eng.1, 129(1979).

31. F.H. Raven, Automatic Control Engineering, 3rd edition (McGraw-Hill, New York, 1978), Chapter 6.

32. K.W. Yee, H.T. Bandy, J. Boudreaux, and N.D. Wilkin, "Automated Compensation of Part Errors Determined by In-Process Gauging" NISTIR 4854 (National Institute of Standards and Technology, Gaithersburg, MD, 1992).

33. H.T. Bandy, "Process-Intermittent Error Compensation," in ref. 6, p. 41.

34. J. Tlusty, S. Smith, and C. Zamudio, "Evaluation of Cutting Performance of Machining Centers," CIRP Annals 40 (1), 405 (1991).

35. I. Minis, R. Yanushevsky, A. Tembo, "Analysis of Linear and Nonlinear Chatter in Milling," CIRP Annals $\underline{39}$ (1), 459 (1990). 


\section{CORRELATIONS BETWEEN COMPONENTS OF ERROR AND MACHINING PROCESS PARAMETERS FOR A TWO-AXIS TURNING MACHINE}

\section{Component of Error Functionality}

$\mathrm{x} \cdot$ direction:

$\begin{array}{ll}\delta_{\mathrm{x}}(\mathrm{s}) & \text { Offset } \\ \delta_{\mathrm{x}}(\mathrm{z}) & \text { Sideways } \\ \epsilon_{\mathrm{y}}(\mathrm{s})^{*} \mathrm{z}(\mathrm{w}) & \text { Sideways } \\ \epsilon_{\mathrm{y}}(\mathrm{z})^{*} \mathrm{Z}_{\mathrm{T}} & \text { Sideways } \\ \delta_{\mathrm{x}}(\mathrm{x}) & \text { Linear } \\ \epsilon_{\mathrm{y}}(\mathrm{x})^{*} \mathrm{Z}_{\mathrm{T}} & \text { Linear }\end{array}$

z-direction:

$\begin{array}{ll}\delta_{\mathrm{z}}(\mathrm{s}) & \text { Offset } \\ \epsilon_{\mathrm{y}}(\mathrm{s})^{*} \mathrm{x}(\mathrm{w}) & \text { Sideways } \\ \epsilon_{\mathrm{y}}(\mathrm{x})^{*} \mathrm{X}_{\mathrm{T}} & \text { Sideways } \\ \delta_{\mathrm{z}}(\mathrm{x}) & \text { Sideways } \\ \delta_{\mathrm{z}}(\mathrm{z}) & \text { Linear } \\ \epsilon_{\mathrm{y}}(\mathrm{z})^{*} \mathrm{X}_{\mathrm{T}} & \text { Linear } \\ \epsilon_{\mathrm{y}}(\mathrm{z})^{*} \mathrm{x} & \end{array}$

$\underline{\text { Relevant Process Parameter }}$

Spindle Temperature

Carriage Temperature

Spindle Temperature, $\propto$ Axial Position $\mathrm{z}(\mathrm{w})^{*}$

Carriage Temperature, $\propto$ Tool Offset $Z_{T}$

Cross Slide Temperature

Cross Slide Temperature, $\propto$ Tool Offset $Z_{T}$

Spindle Temperature

Spindle Temperature, $\propto$ Position $\mathrm{x}(\mathrm{w})$

Cross Slide Temperature, $\propto$ Tool Length $X_{T}$

Cross Slide Temperature

Carriage Temperature

Carriage Temperature, $\propto$ Tool Length $\mathrm{X}_{\mathrm{T}}$

Carriage Temperature, $\propto$ Cross Slide Position $\mathrm{x}$

* $\quad \propto=$ proportional to 


\section{FIGURE CAPTIONS}

1. Architecture of QIA project showing three control loops and a pre-process characterization phase. QM- quality monitor, QC- quality controller, MTC-machinetool controller, MT- machine tool.

2. Overall template for information flow in the QIA architecture.

3. Real-time information flow.

4. Process-intermittent information flow alternatives, adjustment of real-time compensation values or $\mathrm{NC}$ revision.

5. Post-process information flow.

6. Schematic diagram of a two-axis turning center showing major components of quasistatic error.

7. The resultant error components for the tip of the cutting tool with respect to the workpiece.

8. Measured error surface for the z-displacement error in the turning machine used in the QIA project.

9. Example of a tool offset correction in the x-direction.

10. Flowchart of a typical cutting operation including process-intermittent correction.

11. Measurable error features of a turned workpiece.

12. Scenario for correction of shaft straightness in turning. 


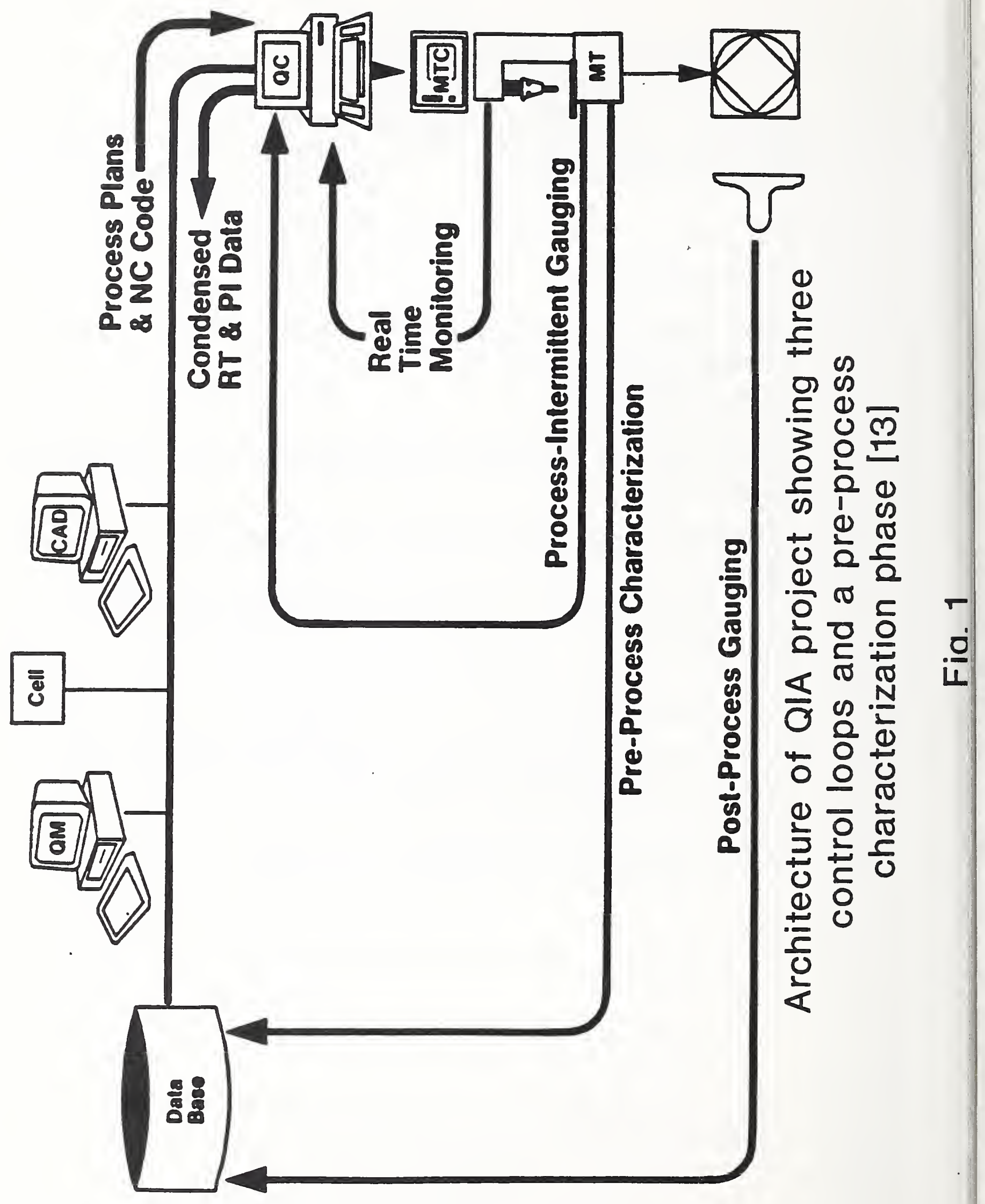




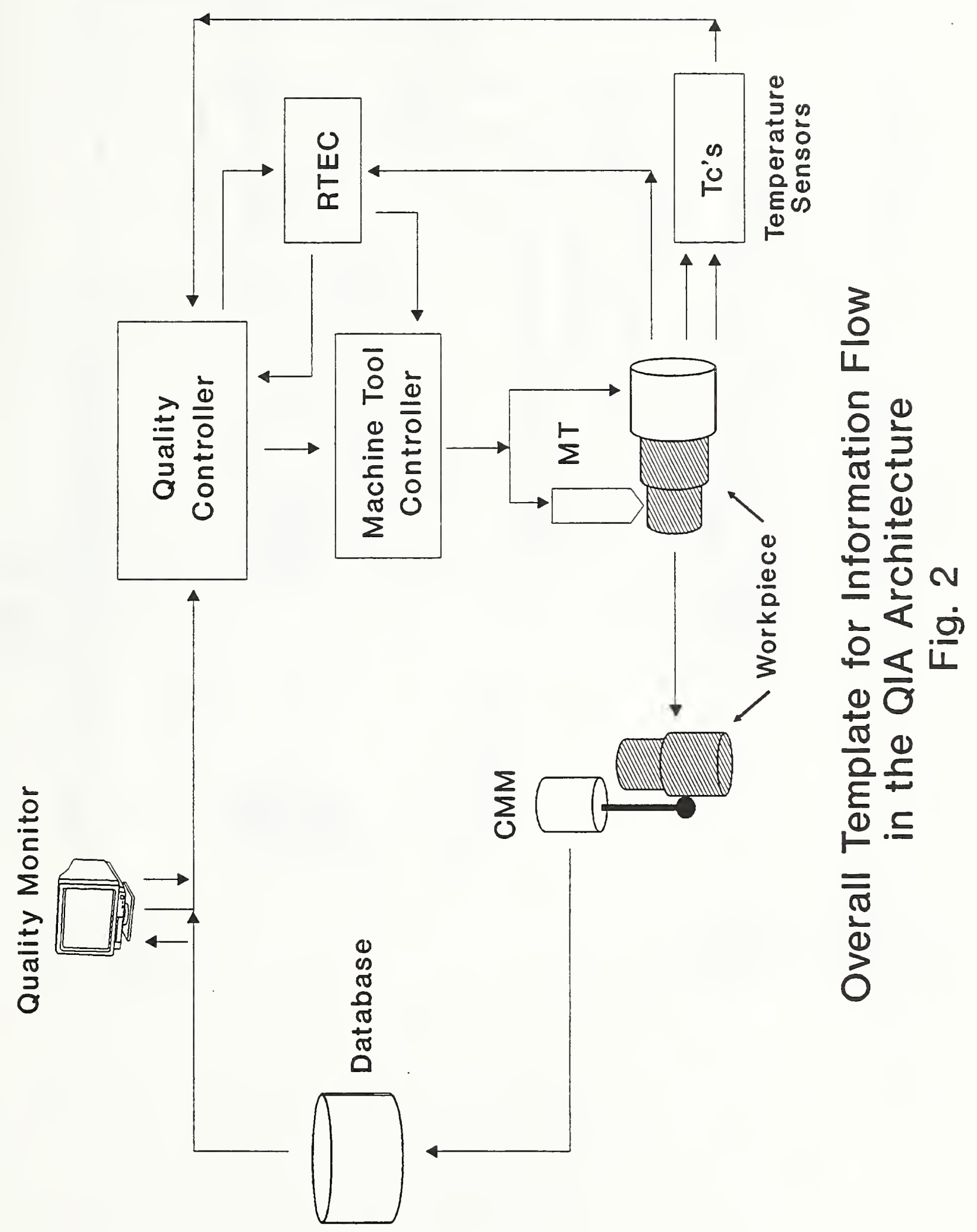



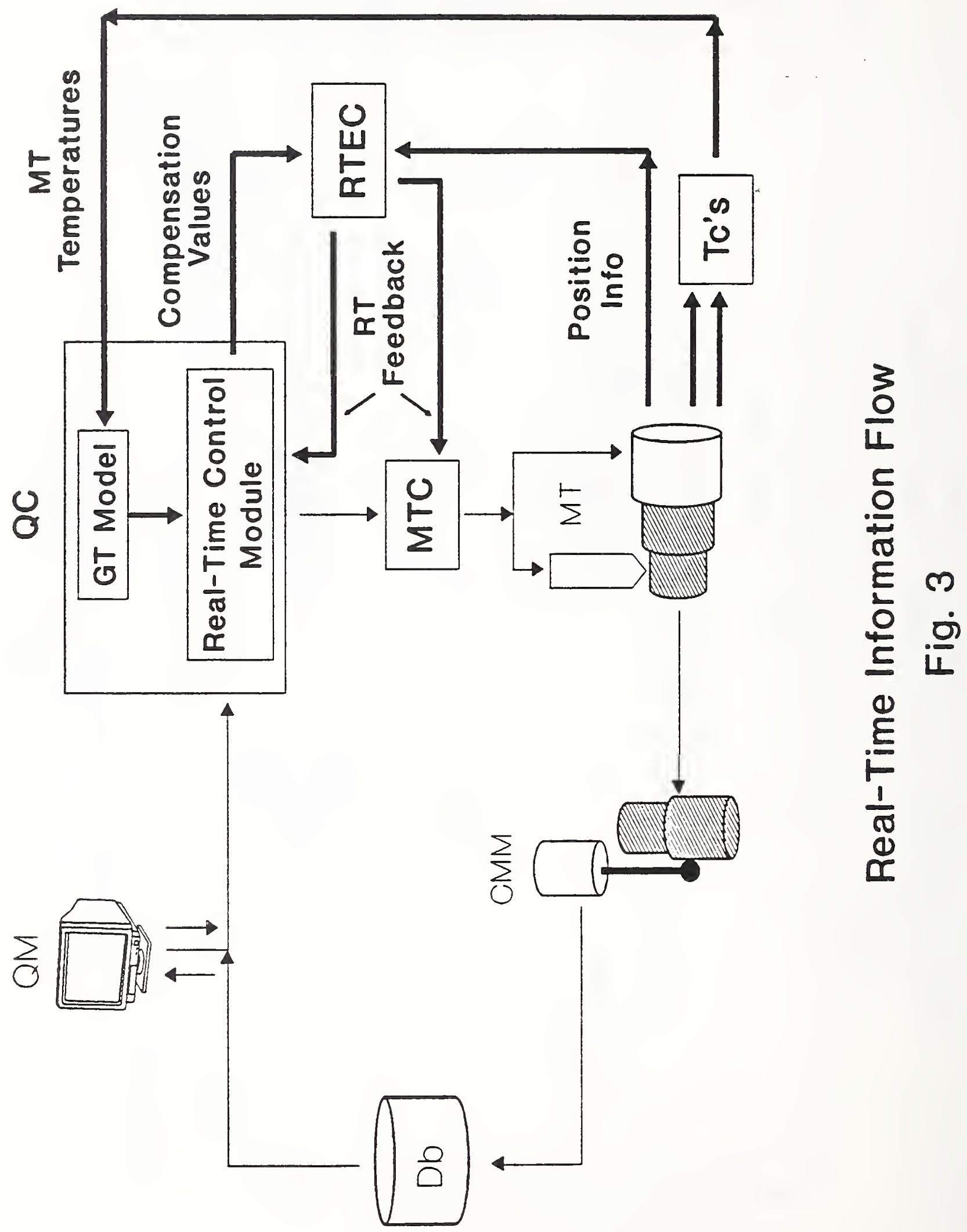


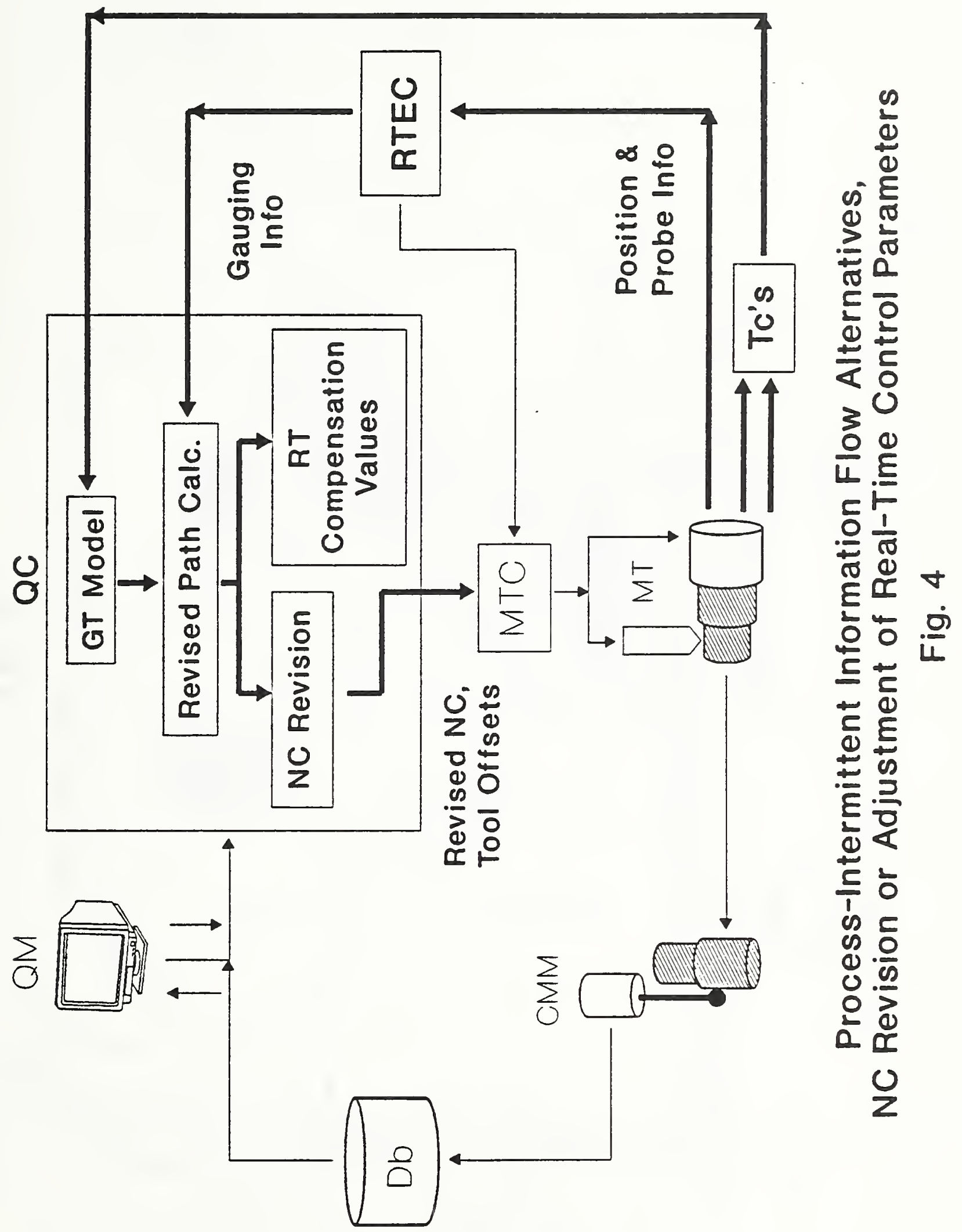



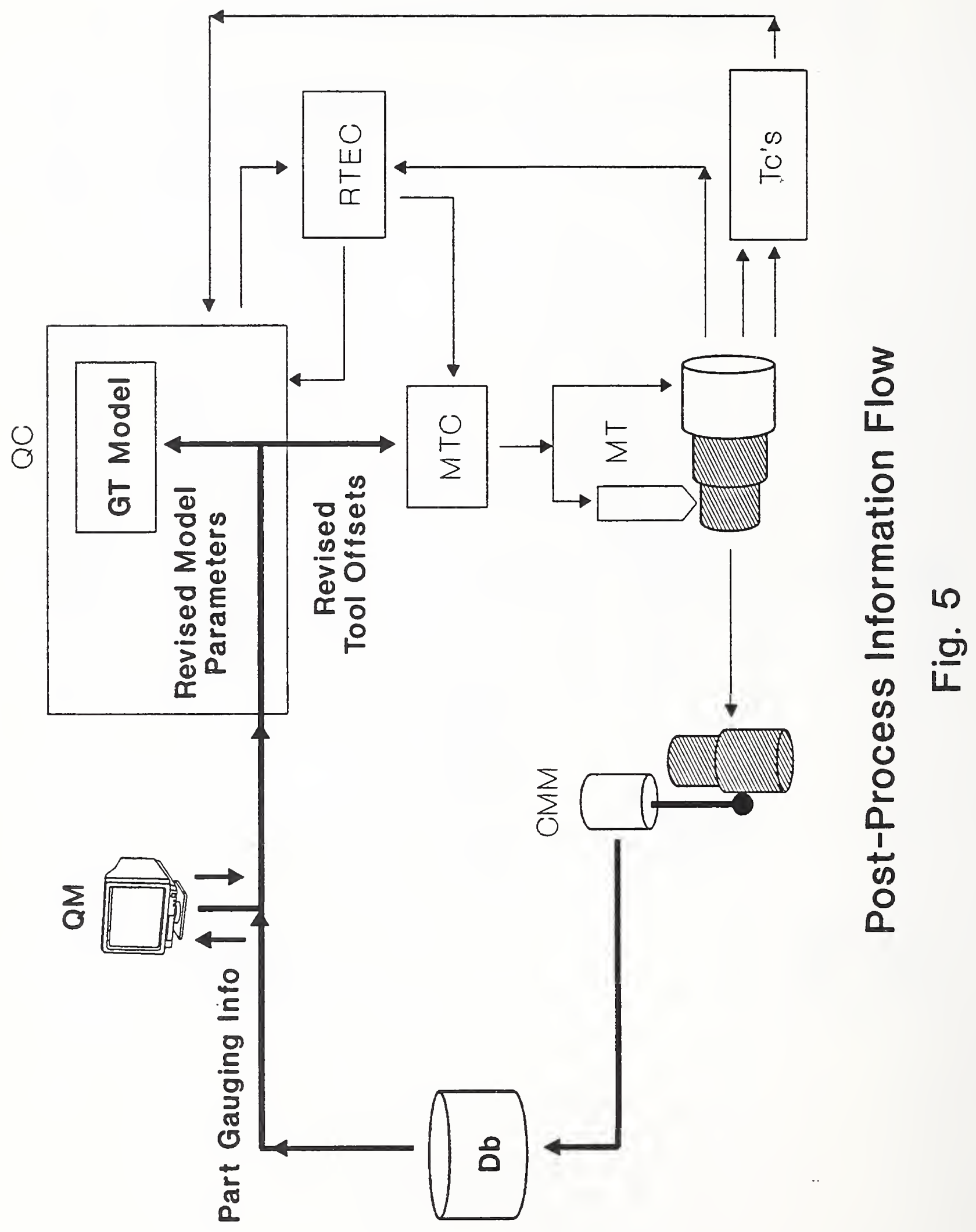


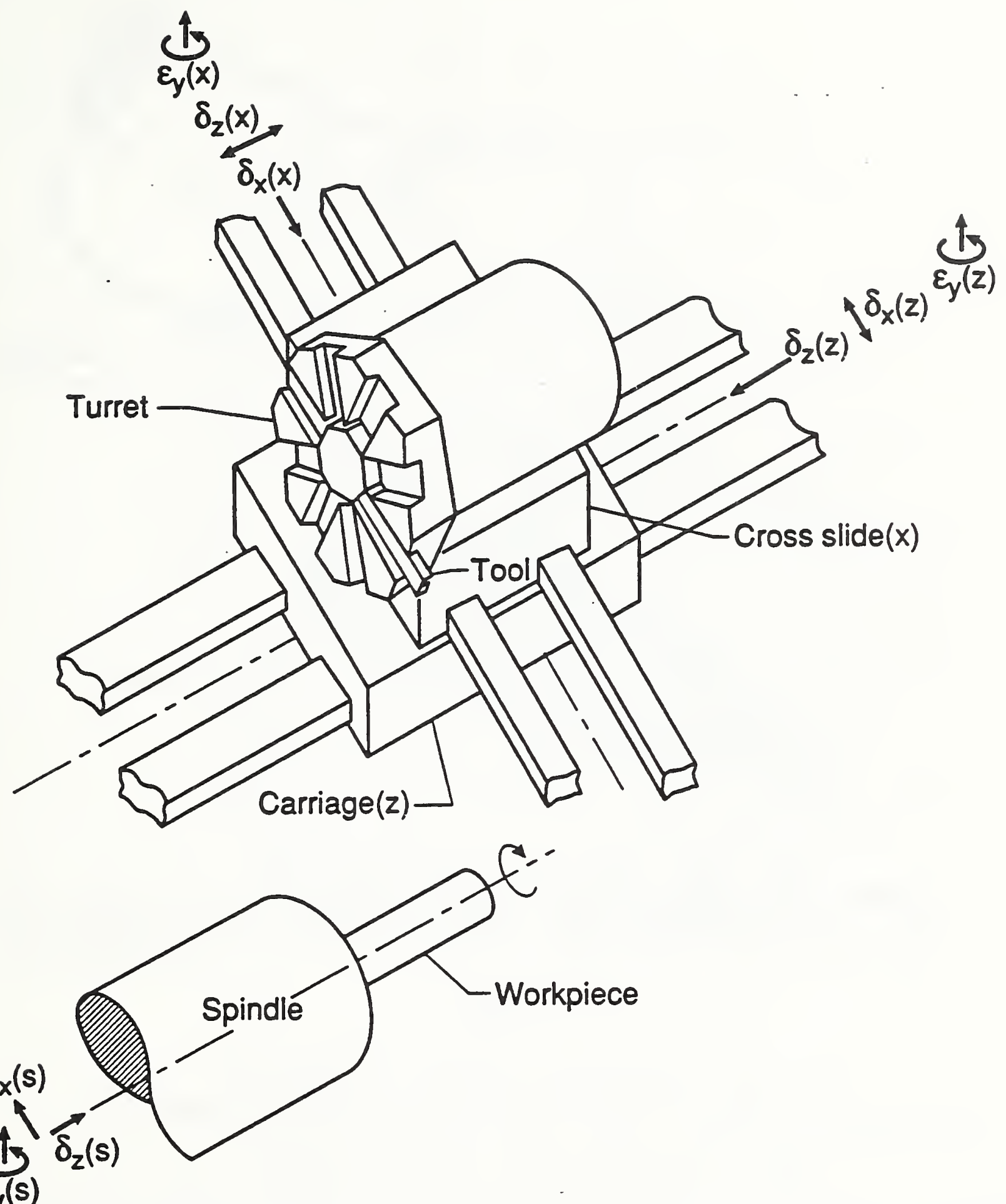

Schematic Diagram of a Two-axis Turning Center Showing Major Sources of Quasistatic Error [15]

Fig. 6 


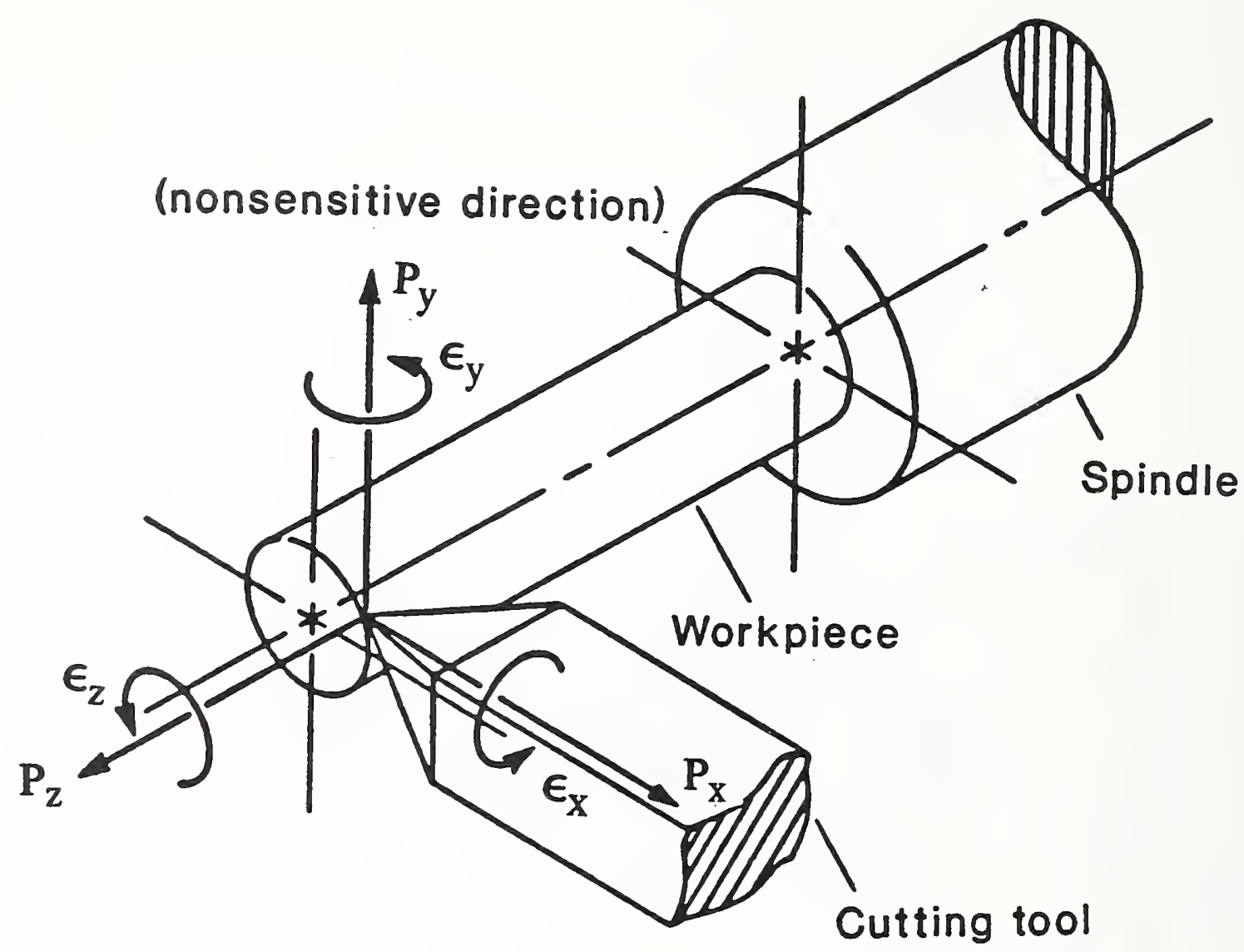

The resultant error components for the tip of the cutting tool with respect to the workpiece [15]

Fig. 7 


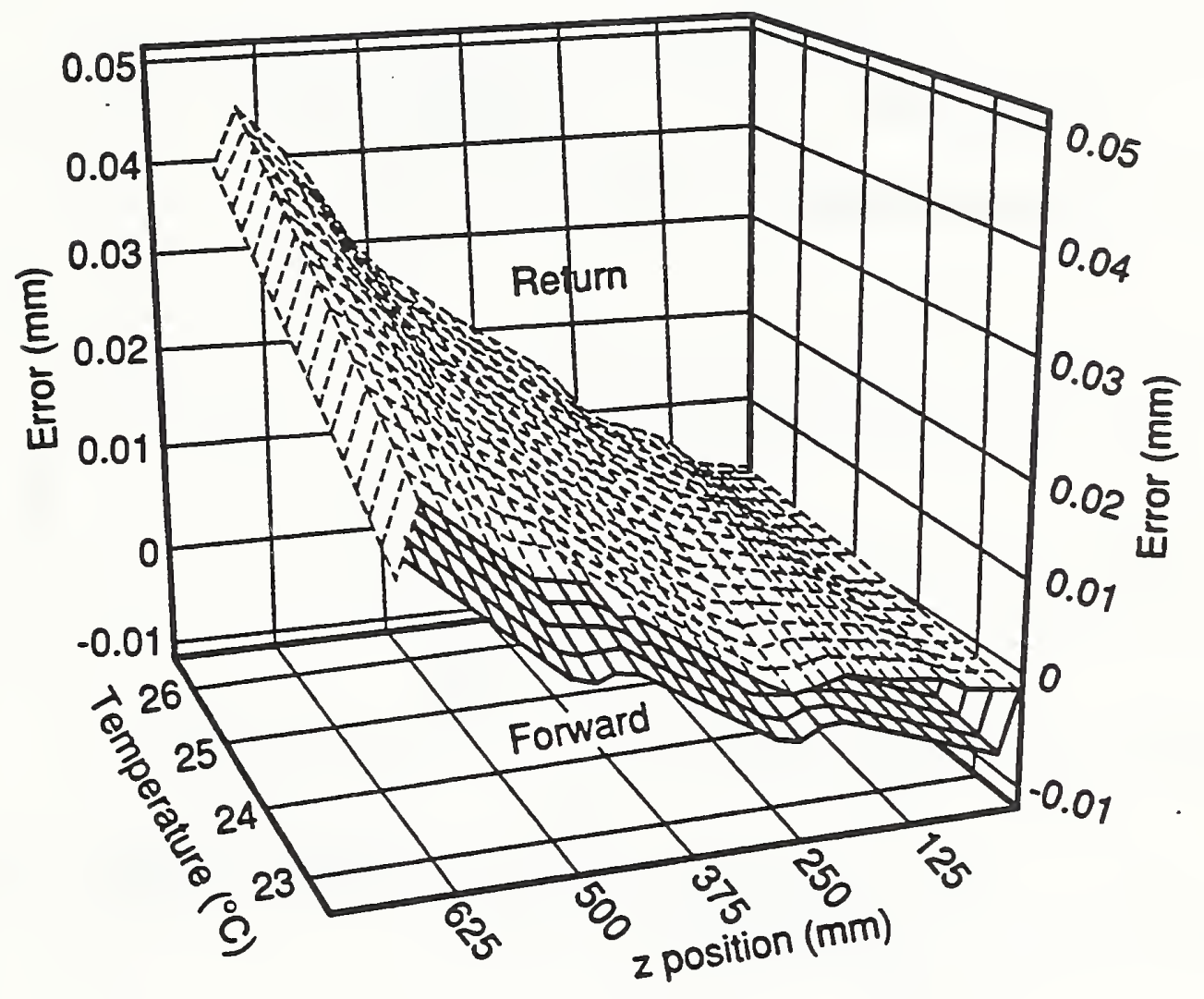

Measured error surface for the $z$-displacement error of the turning machine used in the QIA project [16]

Fig. 8 
$X_{T}=$ Tool Length $=50 \mathrm{~mm}$

$X_{N}=$ Nominal Tool Length $=50 \mathrm{~mm}$

$\Delta_{\mathrm{T}}=$ Offset Parameter $=0$

Intended: $r_{\text {cut }}=35.00 \mathrm{~mm}$

Measured: $r=35.04 \mathrm{~mm}$

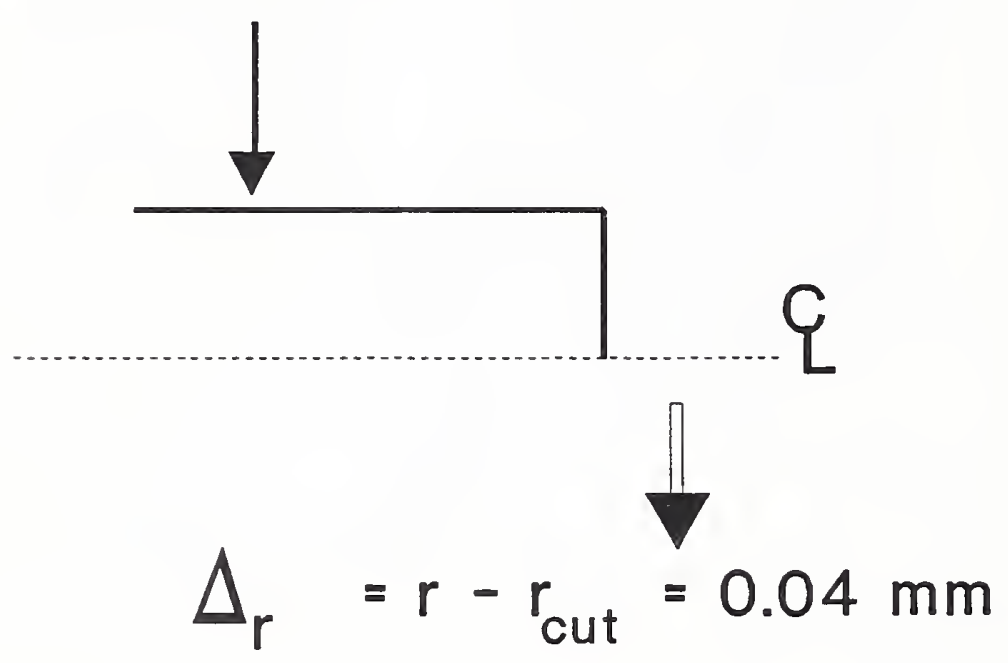

Weighting factor $(w)=0.75$

$\Delta_{T}=w \Delta_{r}$

$X_{T} \Rightarrow X_{N}-\Delta_{T}=49.97 \mathrm{~mm}$

Example of a Tool Offset Correction in the $\mathrm{x}$-direction

Fig. 9 


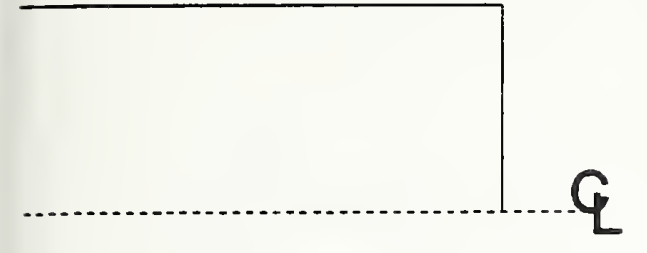

Roughing Semifinish

$\longleftarrow$ Finish
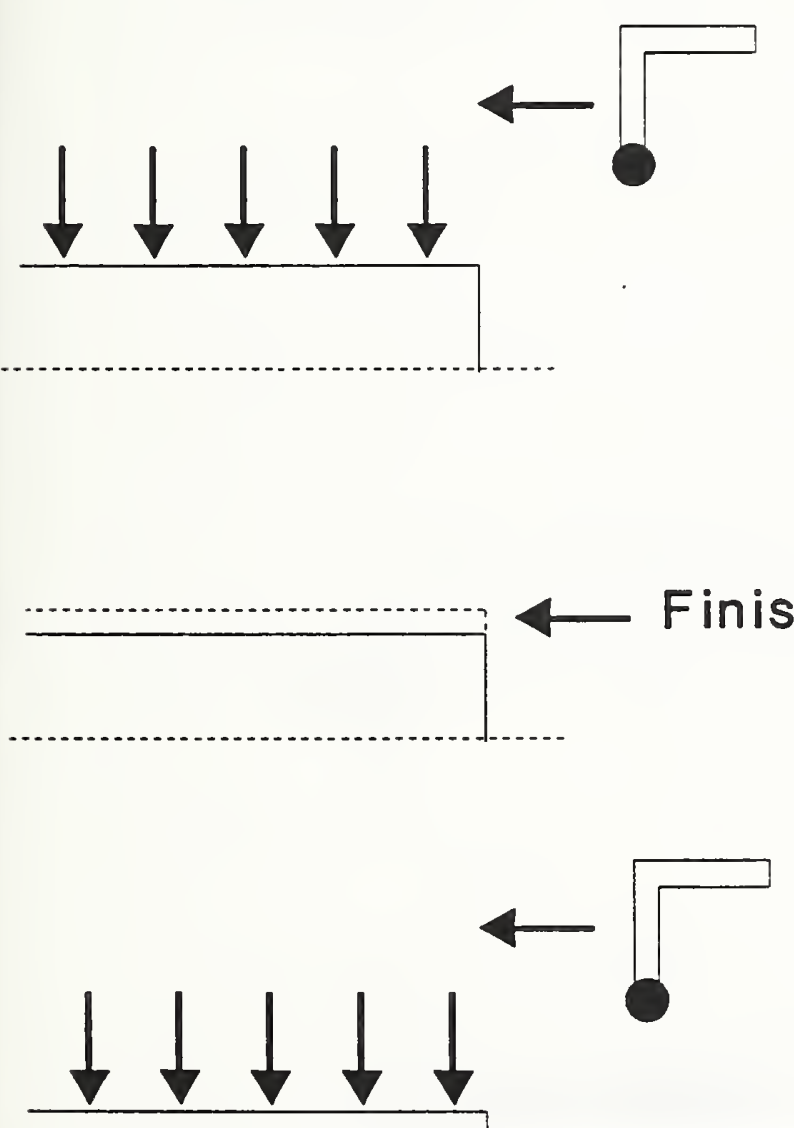

\section{NC Block 1}

downloaded from QC to MTC

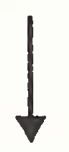

Roughing cuts and semifinish cuts peformed

NC Block 2 downloaded<smiles>CC1([V])CCCCC1</smiles>

Process-Intermittent Gauging of workpiece

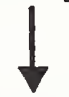

Variables Adjusted in NC Block 3 in QC

NC Block 3 downloaded

Finish cut performed

NC Block 4 downloaded

Gauging of

Finished Turned Feature

Flowchart of a Typical Cutting Operation Including Process-Intermittent Correction

Fig. 10 
a)

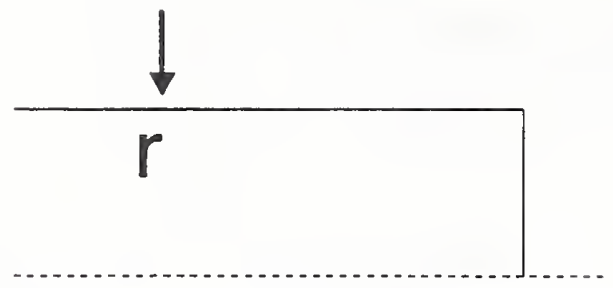

b)

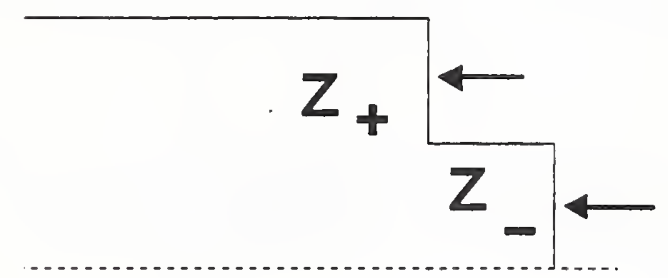

c)

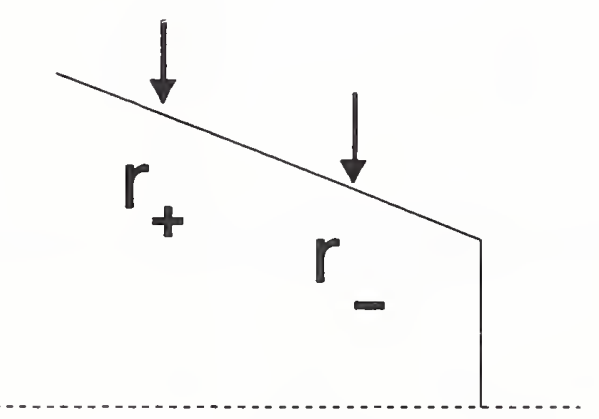

d)

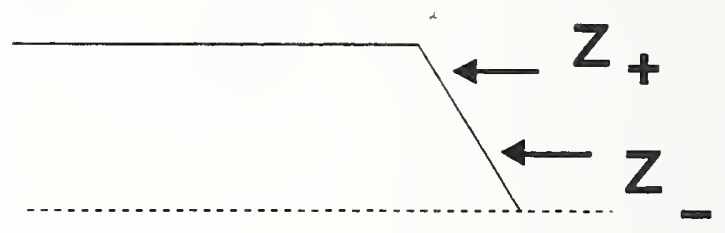

e)

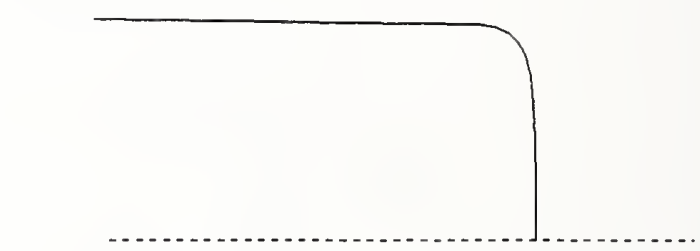

f)

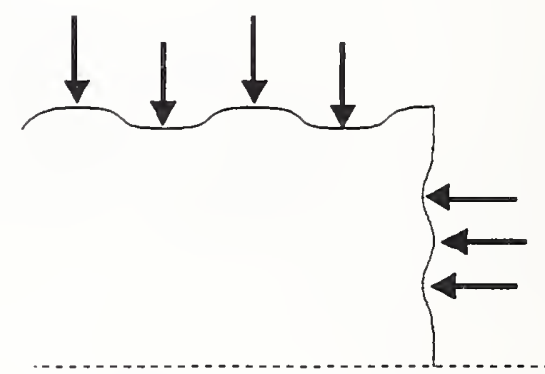

\section{Measurable Error Diagnostics of a Turned Workpiece}

Fig. 11 


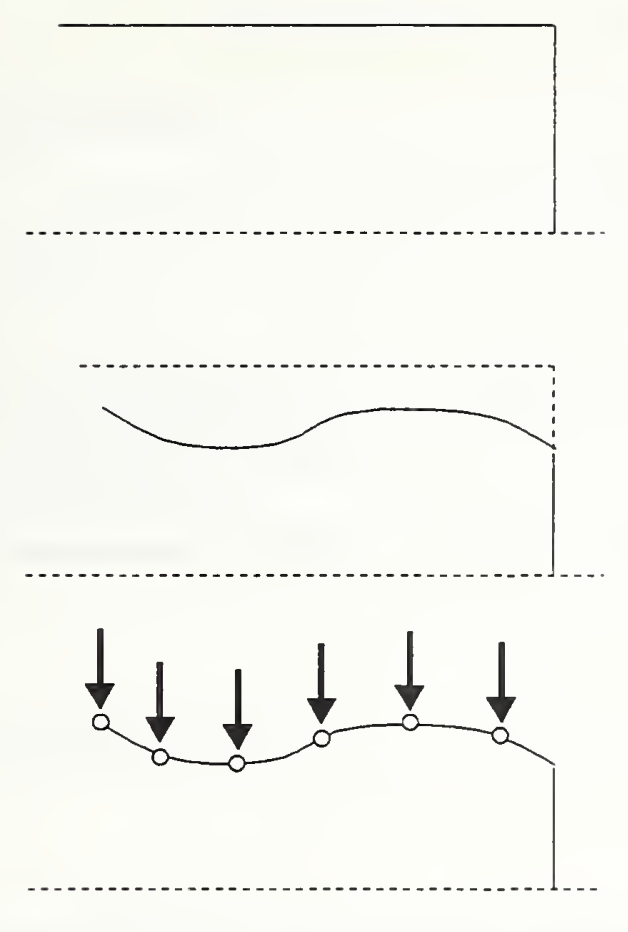

Fixtured Stock

Semifinished Shaft with Error of Form

Process Intermittent Probing

Data Fitted to Polynomial

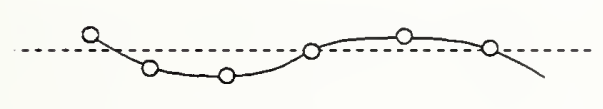
$x=a_{0}+a_{1} z+a_{2} z^{2}+a_{3} z^{3}$

4 Parameters Preselected

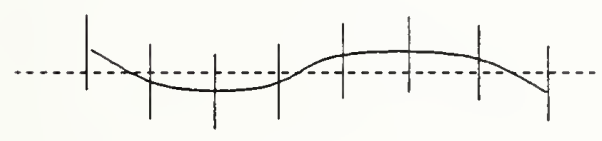

Polynomial $\rightarrow$ :

NC Segments

or

RTEC Compensation Values

Finished Shaft

Scenarios for Correction of Shaft

Straightness in Turning

Fig. 12 

NIST-114A

(REV. 3-90)
U.S. DEPARTMENT OF COMMERCE NATIONAL INSTITUTE OF STANDARDS AND TECHNOLOGY

\section{BIBLIOGRAPHIC DATA SHEET}

1. PUBUCATION OR REPORT NUMBER

NISTIR 4773

2. PERFORMING ORGANIZATION REPORT NUMBER

3. PUBUCATION DATE

SEPTEMBER 1992

\section{TITLE AND SUBTITLE}

A STRATEGY FOR THE QUALITY CONTROL OF AUTOMATED MACHINE TOOLS

\section{AUTHOR(S)}

T.V. Vorburger, K.W. Yee, B.R. Scace, and F.F. Rudder, Jr.

6. PERFORMING ORGANIZATION (IF JOINT OR OTHER THAN NIST, SEE INSTRUCTIONS) U.S. DEPARTMENT OF COMMERCE

MATIONAL INSTITUTE OF STANDARDS AND TECHNOLOGY

GATHERSBURG, MD 20899

7. CONTRACT/GRANT NUMBER

8. TYPE OF REPORT AND PEAIOD COVERED

9. SPONSORING ORGANIZATION MAMEAND COMPLETE ADDRESS (STREET, CITY, STATE, ZIP)

11. ABSTRACT (A 200-WORD OR LESS FACTUAL SUMMARY OF MOST SIGNIFICANT INFORMATION. IF DOCUMENT INCLUDES A SIGNIFICANT BIBUOGRAPHY OR UTERATURE SURVEY, MENTION IT HERE.)

The automated control of machine tool accuracy is discussed within a quality architecture containing three control loops: real-time, process-intermittent, and post-process. This architecture is being implemented at the National Institute of Standards and Technology under the Quality in Automation (QIA) project. One objective of the QIA project is to test the philosophy of deterministic metrology for improving the accuracy of machine tools.

Deterministic metrology relies on repeatability of the process and emphasizes the measurement of process variables over statistical process control of the product. At present, active investigation is being carried out for a two-axis turning center, but the architecture may be applied to a three-axis milling center as well. The strategy for automated correction is focused on five types of adjustable variables in the QIA system: machine offsets, NC code, real-time correction parameters, parameters of a geometrical thermal model, and weighting factors for each of the above quantities. The stages of automating the system are also proposed.

12. KEY WORDS (6 TO 12 ENTRIES; ALPHABETICAL ORDER; CAPITALZE ONLY PROPER NAMES; AND SEPARATE KEY WORDS BY SEMICOLONS) automated manufacturing; competitiveness; CMM; CMC; DMIS; error compensation; inspection; machine tool; probing; process certification; quality control; real-time control.

\section{AVAILABILTYY}

$\mathrm{X}$ UNUMITED

FOR OFFICIAL DISTRIBUTION. DO NOT RELEASE TO NATIONAL TECHNICAL INFORMATION SERVICE (NTIS).

ORDER FROM SUPERINTENDENT OF DOCUMENTS, U.S. COVERNMENT PRINTINC OFFICE, WASHINGTON, DC 20402.

ORDER FROM NATIONAL TECHNICAL INFORMATION SERVCE (NTIS), SPRINGFIELD, VA 22161.
14. NUMBER OF PRINTED PAGES

\section{7}

15. PRICE 

